\title{
The Neuroscience of Natural Rewards: Relevance to Addictive Drugs
}

\author{
Ann E. Kelley ${ }^{1}$ and Kent C. Berridge ${ }^{2}$ \\ ${ }^{1}$ Department of Psychiatry, University of Wisconsin-Madison Medical School, Madison, Wisconsin 53719, and \\ 2Department of Psychology, University of Michigan, Ann Arbor, Michigan 48109-1109
}

Addictive drugs act on brain reward systems, although the brain evolved to respond not to drugs but to natural rewards, such as food and sex. Appropriate responses to natural rewards were evolutionarily important for survival, reproduction, and fitness. In a quirk of evolutionary fate, humans discovered how to stimulate this system artificially with drugs. Many molecular features of neural systems instantiating reward, and of those systems affected by addictive drugs, are conserved across species from Drosophilae to rats to humans and include dopamine (DA), G-proteins, protein kinases, amine transporters, and transcription factors such as cAMP response element-binding protein (CREB). A better understanding of natural brain reward systems will therefore enhance understanding of the neural causation of addiction.

\section{Reinforcers, drives, and incentive systems}

It is first helpful to consider how the field has moved conceptually in recent decades. Although emotions are unobservable, many objective expressions and behavioral, physiological, and neural responses to emotional stimuli have been selected by evolution. Studies of these objective responses in animals and humans provide valuable windows into brain reward function. Early drive theories held that hunger and thirst states motivated behavior directly as aversive drive states and that reinforcers simply reduced those states, strengthening preceding stimulus-response (S-R) habits or increasing the probability of operant response emission. Rewards are recognized now to act at least as importantly as hedonic incentives, causing neural representations that elicit motivation and goal pursuit, rather than as mere habit reinforcers. Physiological drive states nevertheless play important roles in incentive motivation, but primarily by increasing the perceived hedonic and incentive value of the corresponding reward; for example, food tastes better when hungry, drink when thirsty, and so on. Perhaps surprisingly, even drug reward and withdrawal appear to motivate drug-taking behavior primarily via incentive modulation principles rather than directly via simple aversive drives (Stewart and Wise, 1992). Accordingly, it behooves affective neuroscientists to understand the neural basis of incentive properties of rewards.

This work was supported by Grants DA09311, DA04788, and DA13780 from the National Institute on Drug Abuse (A.E.K.) and IBN 0091611 from the National Science Foundation (K.C.B.). We thank Terry Robinson, Sheila Reynolds, Matthew Andrzejewski, and Susana Peciña for helpful suggestions on this manuscript.

Correspondence should be addressed to A. E. Kelley, Department of Psychiatry, University of Wisconsin-Madison Medical School, 6001 Research Park Boulevard, Madison, WI 53719. E-mail: aekelley@facstaff.wisc.edu.

Copyright (C) 2002 Society for Neuroscience $0270-6474 / 02 / 223306-06 \$ 15.00 / 0$
Mesocorticolimbic dopamine: pleasure, reinforcement, reward prediction, incentive salience, or what?

It has long been recognized that reward processing depends on mesocorticolimbic DA systems, comprising DA neurons in the ventral tegmental area (VTA) and their projections to nucleus accumbens (NAc), amygdala, prefrontal cortex (PFC), and other forebrain regions. Major efforts have attempted to specify what function this system contributes. Does mesocorticolimbic DA mediate the pleasure of reward stimuli? This was originally suggested because mesocorticolimbic systems are activated by many natural and drug rewards, and their blockade impairs the behavioral effectiveness of most reinforcers (Wise, 1985). Do mesocorticolimbic projections instead learn and predict the occurrence of rewards? That influential associative hypothesis was based on evidence that DA neurons fire to cues that predict rewards but not to already predicted hedonic rewards (Schultz, 2000). Do mesocorticolimbic DA systems mediate the incentive salience attributed to neural representations of rewards and cues, causing them to become perceived as "wanted" goals? That incentive "wanting" hypothesis was based originally on evidence that mesolimbic DA is not needed to mediate the hedonic impact or "liking" for sweet rewards, or new learning about them, despite its importance for motivated behavior to obtain the same rewards (Berridge and Robinson, 1998). Or finally, does mesocorticolimbic DA involvement in reward pursuit reflect broader functions, such as attention, complex sensorimotor integration, effort, or switching among behavioral programs? Those functions were proposed on the basis of various observations that do not readily fit a pure reward framework (Salamone, 1994; Gray et al., 1999; Ikemoto and Panksepp, 1999; Redgrave et al., 1999; Horvitz, 2000). Each hypothesis has its adherents, although there is recognition that they share important commonalities, and a consensus on motivational incentive function may now be forming.

Gaining a more correct answer to the question of "what does DA do in reward" is of great importance to understanding addiction, because addictive drugs are widely agreed to act primarily, although not exclusively, on brain mesocorticolimbic systems. For example, hedonic theories of addiction assume that mesocorticolimbic DA systems chiefly mediate the intense pleasure of addictive drugs and anhedonia during withdrawal (Volkow et al., 1999; Koob and Le Moal, 2001). Learning-based addiction theories assume sensitized or altered cellular mechanisms of associative S-R learning, and reward predictions cause ingrained drugtaking habits (Di Chiara, 1998; Kelley, 1999; Berke and Hyman, 2000; Everitt et al., 2001). The incentive-sensitization theory of addiction assumes that neural sensitization causes excessive attribution of incentive salience to drug-associated stimuli and acts, 
which makes addicts compulsively "want" to take drugs again (Robinson and Berridge, 1993, 2000; Hyman and Malenka, 2001).

Regarding natural reward contributions to addiction neuroscience, it is notable that all the major hypotheses of mesocorticolimbic DA function studies were proposed originally on the basis of studies of natural reward. Therefore, a better understanding of what DA does for natural rewards will clarify brain mechanisms of drug addiction.

\section{Mesocorticolimbic dopamine: appetitive versus aversive motivation}

Beyond having a role in reward, mesocorticolimbic systems also participate in negative emotional states and aversive motivation. What relation could negative motivation (other than withdrawal) have to addiction? Aversive symptoms of psychosis, paranoia, or anxiety are sometimes precipitated in human addicts and in animal models by drugs such as amphetamine or cocaine (Ettenberg and Geist, 1993), but how can a brain "reward system" also mediate negative motivation and emotion? Some hypotheses suggest that mesocorticolimbic systems mediate general functions, such as attention or sensorimotor integration, and not reward or aversion specifically (Salamone, 1994; Gray et al., 1999; Horvitz, 2000). Another hypothesis is that DA responses to aversive motivation reflect hidden incentive mechanisms involved in the pursuit of safety (Rada et al., 1998; Ikemoto and Panksepp, 1999), drawing on psychological theories of avoidance learning. In other words, active pursuit of food when hungry or of safety when in danger could involve similar mesocorticolimbic incentive processes. However, most researchers probably support a third hypothesis that certain mesocorticolimbic systems play an active role in aversive motivation itself, distinct from DA mediation of reward (Salamone, 1994; Berridge and Robinson, 1998; Gray et al., 1999).

Several lines of evidence indicate direct mesocorticolimbic mediation of aversive motivation. Mesocorticolimbic brain systems are activated in animals and humans by aversive stimuli such as stress, electric shocks, etc. (Piazza et al., 1996; Becerra et al., 2001). Amphetamine administration enhances aversive associative conditioning of behavioral responses (Gray et al., 1999), whereas lesions of the NAc core disrupt conditioning of aversive responses to Pavlovian cues (Parkinson et al., 1999). Negative motivation versus reward may be mediated by different mesocorticolimbic channels of information processing. Neuroanatomical and neurochemical segregation of valence are indicated by observations that GABAergic microinjections in the NAc shell can elicit either intense positive motivation or negative motivation, depending on the shell subregion. GABA agonist microinjections in the anterior medial shell elicit appetitive eating behavior, but the same microinjections in the posterior medial shell elicit fearful defensive treading (Stratford and Kelley, 1999; Reynolds and Berridge, 2001), a behavior normally reserved by rodents in the wild for noxious stimuli such as threatening rattlesnakes (Treit et al., 1981; Coss and Owings, 1989; Owings and Morton, 1998). Further clarification of how mesocorticolimbic subsystems code positive versus negative motivational states should be a high priority as a means to shed light on why drugs of abuse sometimes produce mixed motivational effects, including anxiety and susceptibility to psychosis.

\section{Natural rewards as windows into reward "liking" versus reward "wanting"}

Although drug addicts want to take drugs more than other people, they may not proportionately like those drugs more, especially if neuropharmacological tolerance grows to their pleasurable impact; however, distinctions between neural systems of "wanting" reward and "liking" reward have emerged most clearly from studies of natural rewards, especially sweet taste reward, where it is possible to use affective facial expressions to measure immediate "liking" or hedonic impact. In human infants (Fig. 1), sucrose taste elicits a set of facial "liking" expressions (tongue protrusions, smile, etc), whereas quinine taste elicits facial "disliking" expressions (gape, etc.) (Steiner et al., 2001). Comparisons of human infant expressions with those of at least 11 great ape and monkey species indicate that primate expression patterns for "liking" and "disliking" are characterized by strong taxonomic continuity across species and by homology of microstructure features, such as allometric control of component speed (Steiner et al., 2001). Even rats display these reactions to tastes that reflect core affective processes and hedonic neural mechanisms homologous to those of humans (Grill and Norgren, 1978; Berridge, 2000).

Opioid peptide neurotransmission within the NAc modulates the hedonic impact of food reward (Glass et al., 1999; Peciña and Berridge, 2000; Kelley et al., 2002), providing further support that drugs of abuse act on systems evolved to mediate such natural pleasures as sweetness "liking." For example, microinjection of morphine into NAc shell directly increases rat "liking" orofacial expressions elicited by sucrose (Peciña and Berridge, 2000) and alters intake consistent with enhanced food palatability (Zhang and Kelley, 2000). Such findings demonstrate the importance of neurochemical systems other than dopamine in the hedonic impact of rewards.

Originally surprising were findings that mesocorticolimbic DA manipulations do not change "liking" for the taste of sucrose (Peciña et al., 1997; Wyvell and Berridge, 2000), despite their role in incentive "wanting" for these and other rewards. The neurochemical dissociation of "liking" from "wanting" has obvious relevance to addiction. The incentive-sensitization theory suggests that addiction may be characterized by increased "wanting" of drugs caused by sensitized DA-related systems, even in the absence of drug "liking" (Robinson and Berridge, 2000; Hyman and Malenka, 2001).

\section{From nodes to dynamic networks}

Reward-related behavior emerges from the dynamic activity of entire neural networks rather than from any single brain structure. The functions of NAc, amygdala, etc., in natural reward or addiction can be understood only in terms of the extended neural system within which they reside (Fig. 2). Although we now have a working knowledge of key brain structures of reward, deeper understanding will require examination of network interactions between subregions of amygdala, PFC, NAc, and other structures in reward and motivation (Kalivas and Nakamura, 1999; Rolls, 1999; Everitt et al., 2000; Schultz, 2000; Jackson and Moghaddam, 2001). For example, amygdala and orbital prefrontal cortex may play complementary roles in reward learning regarding acquisition of cue incentive value versus response selection (Schoenbaum et al., 1999; Baxter et al., 2000).

A further network feature concerns the efferent projections of NAc to target structures such as lateral hypothalamus and ventral pallidum. This outflow appears crucial to NAc mediation of natural appetitive behavior (Kalivas and Nakamura, 1999; Stratford and Kelley, 1999; Zahm, 2000). Elicitation of eating behavior by inhibition of spiny neurons in the NAc shell depends on signals to the lateral hypothalamus, which activates lateral hypothalamic 

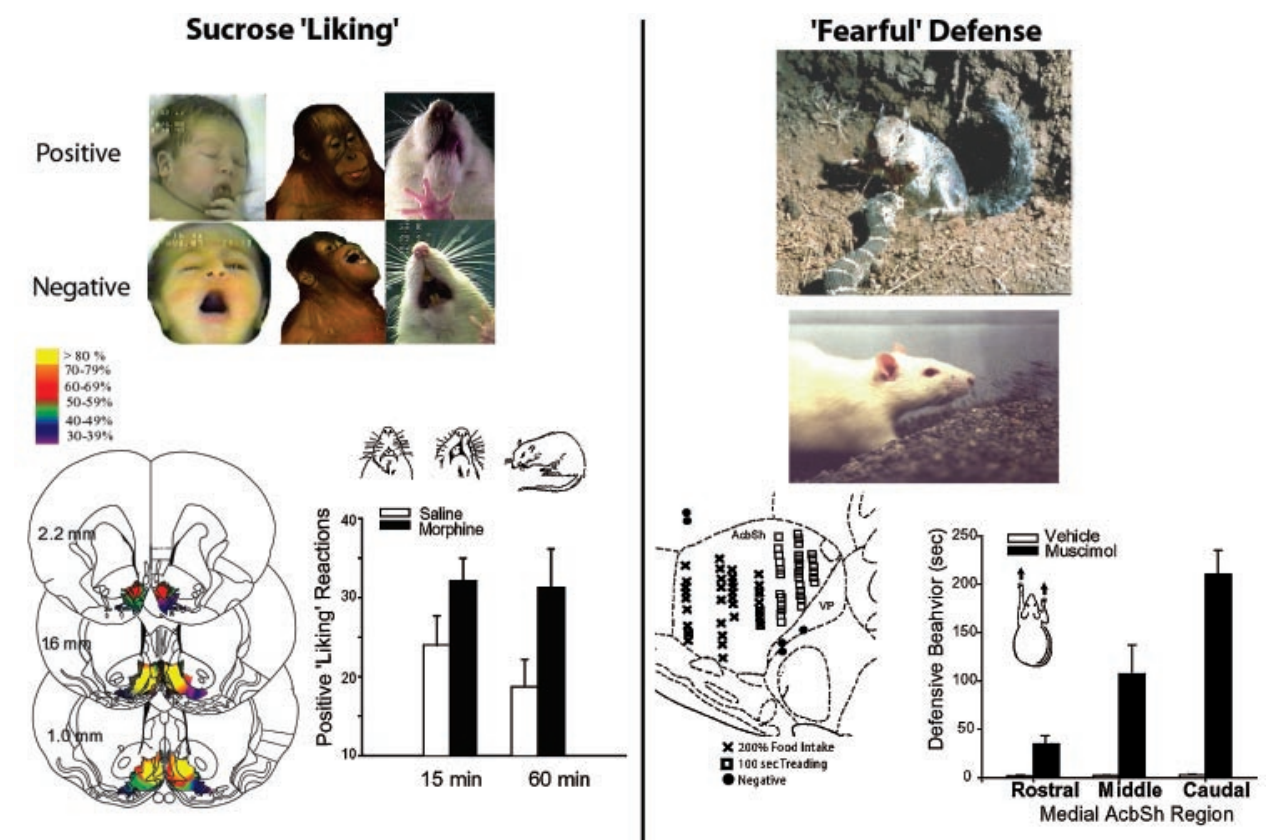

Figure 1. Naturalistic behavior assays of reward liking and negative fearful defense. Liking facial expressions are elicited by the taste of sucrose from newborn human infants, orangutans, and rats [top left, facial photographs from Steiner et al. (2001) and Berridge (2000)]. Disliking expressions are elicited by the taste of quinine. NAc coronal map of opioid liking and wanting sites for food reward shows intensity of food wanting produced by morphine microinjections in the shell [bottom left, Peciña and Berridge (2000)]. Accompanying graph shows the increase in sucrose liking reactions caused by morphine microinjections in the accumbens shell. Conversely, anxiogenic and psychotic effects of addictive drugs may be related to natural fearful active defense reactions (right). Fearful defensive treading is elicited naturally from rodents by rattlesnake predators and centrally by GABA agonist microinjections in the caudal accumbens shell [California ground squirrel photograph by John Cooke from Coss and Owings (1989); rat photograph from Reynolds and Berridge (2001)]. Bar graph shows elicitation of fearful defensive treading along a rostrocaudal gradient in the NAc shell after GABA agonist microinjections (Reynolds and Berridge, 2001). Separate mesocorticolimbic channels for appetitive and aversive motivational functions is suggested by sagittal map of NAc shell rostrocaudal segregation of GABA-elicited positive feeding behavior (anterior $x$ symbols) versus fearful defensive behavior (posterior squares). neurons via disinhibition (Rada et al., 1997; Stratford and Kelley, 1999). Thus, the NAc shell may gate corticolimbic information to the lateral hypothalamus and exert executive control over brain circuits controlling feeding behavior and related motivation (Kelley, 1999; Petrovich et al., 2001). This corticostriatal-hypothalamic-brainstem network deserves to be the focus of further study, in the contexts of both natural reward and addiction (Swanson, 2000).

\section{Neural ensembles and behavioral selection}

Dynamic modulation of incentive value emerges from afferent network signals that cause variation in the states of individual medium spiny NAc neurons. For example, these neurons exhibit "bistable" membrane potential states, which depend on phasic excitatory glutamatergic input from afferent structures such as hippocampus (O'Donnell and Grace, 1995). NAc neurons are depolarized by PFC input when they are in the hippocampalgated "up" state, and thus network synchrony arises between NAc and hippocampus (Goto and O'Donnell, 2001). Similar gating of NAc neurons may occur between amygdala and hippocampal inputs (Mulder et al., 1998; Floresco et al., 2001b). DA input also plays a critical role in the NAc switching and is influenced in turn by hippocampal glutamatergic input to VTA (Legault and Wise, 2001). Thus, dynamic modulation by incoming network signals can control which NAc motivational ensembles predominate to guide behavior toward natural or drug rewards.

\section{Network plasticity mediated by DA-glutamate interactions}

Addictive drugs induce long-term neuroadaptations at the structural, cellular, molecular, and genomic levels (Hyman and Malenka, 2001), but how does such plasticity relate to natural reward and motivation? An exciting synthesis is emerging from studies of glutamate-DA-mediated plasticity and its transcriptional consequences. Coincident activation of DA D1 receptors and glutamate NMDA receptors plays a critical role in shaping synaptic configurations and neural ensembles involved in motivation and learning.

In both striatum and PFC, D1 activation potentiates NMDA responses (Seamans et al., 2001; Wang and O'Donnell, 2001), and long-term potentiation at hippocampal-prefrontal cortex synapses is dependent on coactivation of NMDA and D1 receptors and on intracellular cascades involving protein kinase A (Gurden et al., 2000). Sensitization by drugs of abuse is facilitated by a related glutamate-dopamine interaction caused when drugs are administered in a novel distinct environment (Uslaner et al., 2001). In accumbens neurons, cooperative action of both D1 and NMDA receptors mediates hippocampal-evoked spiking activity (Floresco et al., 2001b), and a similar synergism is observed for the amygdalo-accumbens pathway (Floresco et al., 2001a). Molecular studies complement these findings, showing NMDAreceptor dependence of D1-mediated phosphorylation of CREB (Konradi et al., 1996; Das et al., 1997), a transcription factor thought to be an evolutionarily conserved modulator of memory processes. Transcriptional consequences of NMDA and D1 coactivation in the NAc core and PFC are necessary for appetitive learning about cues, rewards, and behavioral actions, particularly at early acquisition stages (Baldwin et al., 2000, 2002a,b; SmithRoe and Kelley, 2000). In sum, coordinated activation of DA D1 and NMDA systems within corticolimbic-striatal circuits is an important feature of adaptive reward learning.

This story suggests that drugs of abuse that target DA and glutamate synapses should enduringly modify basic cellular and molecular functions. Such long-lasting plasticity in reward neurons induced by drugs may contribute to abnormal information processing and behavior, resulting in poor decision making, loss of control, and the compulsivity that characterizes addiction. That drugs of abuse induce D1- and NMDA-mediated neuronal cascades shared with normal reward learning is an important insight regarding addiction that has emerged in the past decade. 


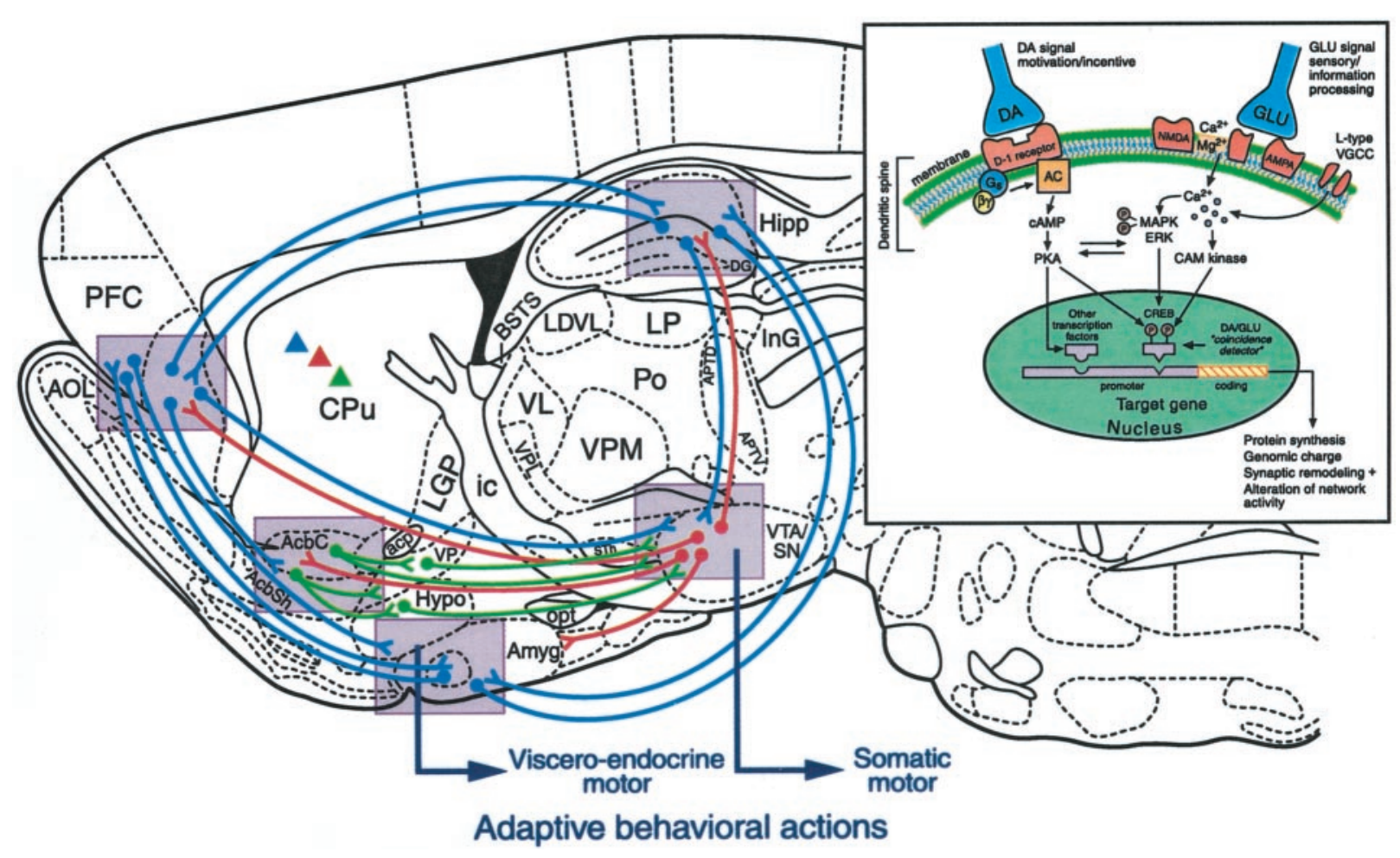

Figure 2. Schematic representation of rat brain sagittal section depicting pathways involved in processing of natural rewards and in neural plasticity underlying reward-related learning. Circuitry represented in blue indicates long glutamatergic pathways between prefrontal cortex (PFC), amygdala (Amyg), hippocampus (Hipp), ventral striatum (nucleus accumbens), and ventral tegmental area (VTA). Red circuitry represents principal ascending mesocorticolimbic dopamine systems. Green descending pathways indicate primarily GABAergic descending systems. Triangles in corresponding colors indicate similar DA, glutamate, and GABAergic coding in dorsal striatum. Violet-shaded boxes represent important nodes within this distributed network where NMDA/D1 receptor-mediated plasticity is proposed to be a critical substrate for behavioral adaptation and learning. For purposes of simplicity, not all relevant circuitry is shown; for example, there are important connections between hypothalamus and amygdala, and glutamatergic thalamic inputs are not shown. Drawing of section is based on the atlas of Paxinos and Watson (1998). Large arrows indicate flow of effector pathways converging on viscero-endocrine and autonomic systems (emerging from hypothalamus and amygdala) and somatic voluntary motor systems (emerging from basal ganglia and ventral midbrain). Inset reflects intracellular and genomic mechanisms hypothesized to govern DA- and glutamate-dependent plasticity within the indicated (violet shaded) nodes. Such plasticity, which may result in altered network activity, is hypothesized to mediate normal learning and memory related to natural rewards but is also a key component of addiction. $A c b C$, Accumbens core; $A c b$ shell, accumbens shell; $C p u$, caudate-putamen; $V P$, ventral pallidum; Hypo, hypothalamus; $S N$, substantia nigra. Other abbreviations can be found in Paxinos and Watson (1998).

\section{Reward outside traditional limbic network?}

Although little studied, reward may also be significantly processed in brain structures not traditionally considered mesocorticolimbic, motivational, or related to addiction. For example, "motor" regions of caudate-putamen contain neurons that respond to food and drink reward stimuli, in a manner similar to DAergic or ventral striatal neurons (Aosaki et al., 1994; Schultz, 2000). Eating can be elicited in rats directly by microinjections of opioid agonists into these same motor regions of dorsal striatum (Zhang and Kelley, 2000). Eating is disrupted by DA receptor blockade or lesions in the same dorsal striatal regions (Cousins and Salamone, 1996). Sensorimotor regions of striatum undergo dynamic changes during rewarded "habit" learning (Jog et al., 1999), and their damage impairs learning (Packard and White, 1990). Such evidence suggests that "sensorimotor" structures may participate in natural reward functions to a surprising degree (White, 1989). If so, such extended neural reward processing has implications for addiction as well.

\section{Conclusion}

Drugs can impact natural brain reward systems to produce addiction in only three ways. (1) Drug rewards might activate the same brain systems as intense natural rewards. Addiction theories based on pleasurable drug hedonia or positive reinforcement suppose that drugs act as natural rewards. (2) Addictive drug rewards might also change the quantitative scaling of some reward components, fragmenting and distorting normal reward processes to cause compulsive behavior. Addiction theories based on sensitization of incentive salience propose that drugs sensitize mesocorticolimbic substrates of incentive salience, fractionating natural reward by intensifying "wanting" disproportionately to cause compulsive drug taking behavior (Robinson and Berridge, 2000; Hyman and Malenka, 2001). Addiction theories based on associative long-term potentiation or alterations in learning systems propose unusually strong drug-taking S-R habits (O'Brien et al., 1992; Di Chiara, 1998; Robbins and Everitt, 1999; Berke and Hyman, 2000; Everitt et al., 2001). (3) Addictive drugs could induce new brain processes, such as aversive withdrawal states, which may play larger opponent-process roles for addiction than for normal rewards (Solomon and Corbit, 1974; Koob and Le Moal, 2001).

These three possibilities are exhaustive but not mutually exclusive. Many intriguing facts have been discovered that illuminate their interaction. Future studies will further clarify how drugs interact with brain reward systems to produce the compulsive motivation and relapse that characterize addiction. 


\section{REFERENCES}

Aosaki T, Graybiel AM, Kimura M (1994) Effect of the nigrostriatal dopamine system on acquired neural responses in the striatum of behaving monkeys. Science 265:412-415.

Baldwin AE, Holahan MR, Sadeghian K, Kelley AE (2000) $N$-methy-Daspartate receptor-dependent plasticity within a distributed corticostriatal network mediates appetitive instrumental learning. Behav Neurosci 114:1-15.

Baldwin AE, Sadeghian K, Holahan MR, Kelley AE (2002a) Appetitive instrumental learning is impaired by inhibition of cAMP-dependent protein kinase within the nucleus accumbens. Neurobiol Learn Mem 77:44-62.

Baldwin AE, Sadeghian K, Kelley AE (2002b) Appetitive instrumental learning requires coincident activation of NMDA and DA D1 receptors within medial prefrontal cortex. J Neurosci 22:1073-1071.

Baxter MG, Parker A, Lindner CC, Izquierdo AD, Murray EA (2000) Control of response selection by reinforcer value requires interaction of amygdala and orbital prefrontal cortex. J Neurosci 20:4311-4319.

Becerra L, Breiter HC, Wise R, Gonzalez RG, Borsook D (2001) Reward neural circuitry activation by noxious neural stimulation. Neuron 32:927-946.

Berke JD, Hyman SE (2000) Addiction, dopamine, and the molecular mechanisms of memory. Neuron 25:515-532.

Berridge KC (2000) Measuring hedonic impact in animals and infants: microstructure of affective taste reactivity patterns. Neurosci Biobehav Rev 24:173-198.

Berridge KC, Robinson TE (1998) What is the role of dopamine in reward: hedonic impact, reward learning, or incentive salience? Brain Res Rev 28:309-369.

Coss RG, Owings DH (1989) Rattler battlers. Nat Hist 30-35.

Cousins MS, Salamone JD (1996) Involvement of ventrolateral striatal dopamine in movement initiation and execution: a microdialysis and behavioral investigation. Neuroscience 70:849-859.

Das S, Grunert M, Williams L, Vincent SR (1997) NMDA and D1 receptors regulate the phosphorylation of CREB and the induction of c-fos in striatal neurons in primary culture. Synapse 25:227-233.

Di Chiara G (1998) A motivational learning hypothesis of the role of mesolimbic dopamine in compulsive drug use. J Psychopharmacol 12:54-67.

Ettenberg A, Geist TD (1993) Qualitative and quantitative differences in the operant runway behavior of rats working for cocaine and heroin reinforcement. Pharmacol Biochem Behav 44:191-198.

Everitt BJ, Cardinal RN, Hall J, Parkinson JA, Robbins TR (2000) Differential involvement of amygdala subsystems in appetitive conditioning and drug addiction. In: The amygdala: a functional analysis (Aggleton JP, ed), pp 353-390. Oxford: Oxford UP.

Everitt BJ, Dickinson A, Robbins TW (2001) The neuropsychological basis of addictive behaviour. Brain Res Rev 36:129-138.

Floresco SB, Blaha CD, Yang CR, Phillips AG (2001a) Dopamine D1 and NMDA receptors mediate potentiation of basolateral amygdalaevoked firing of NAc neurons. J Neurosci 21:6370-6376.

Floresco SB, Blaha CD, Yang CR, Phillips AG (2001b) Modulation of hippocampal and amygdalar-evoked activity of nucleus accumbens neurons by dopamine: cellular mechanisms of input selection. J Neurosci 21:2851-2860.

Glass MJ, Billington CJ, Levine AS (1999) Opioids and food intake: distributed functional neural pathways? Neuropeptides 33:360-368.

Goto Y, O'Donnell P (2001) Network synchrony in the nucleus accumbens in vivo. J Neurosci 21:4498-4504.

Gray JA, Kumari V, Lawrence N, Young AMJ (1999) Functions of the dopamine innervation of the nucleus accumbens. Psychobiology 27:225-235.

Grill HJ, Norgren R (1978) The taste reactivity test. I. Mimetic responses to gustatory stimuli in neurologically normal rats. Brain Res 143:263-279.

Gurden H, Takita M, Jay TM (2000) Essential role of D1 but not D2 receptors in the NMDA receptor-dependent long-term potentiation at hippocampal-prefrontal cortex synapses in vivo. J Neurosci 20:RC106(1-5).

Horvitz JC (2000) Mesolimbocortical and nigrostriatal dopamine responses to salient non-reward events. Neuroscience 96:651-656.

Hyman SE, Malenka RC (2001) Addiction and the brain: the neurobiology of compulsion and its persistence. Nat Rev Neurosci 2:695-703.

Ikemoto S, Panksepp J (1999) The role of nucleus accumbens dopamine in motivated behavior: a unifying interpretation with special reference to reward-seeking. Brain Res Rev 31:6-41.

Jackson ME, Moghaddam B (2001) Amygdala regulation of nucleus accumbens dopamine output is governed by the prefrontal cortex. J Neurosci 21:676-681.

Jog MS, Kubota Y, Connolly CI, Hillegaart V, Graybiel AM (1999) Building neural representations of habits. Science 286:1745-1749.

Kalivas PW, Nakamura M (1999) Neural systems for behavioral activation and reward. Curr Opin Neurobiol 9:223-227.

Kelley AE (1999) Neural integrative activities of nucleus accumbens subregions in relation to motivation and learning. Psychobiology 27:198-213

Kelley AE, Bakshi V, Haber SN, Steininger TL, Will MJ, Zhang M (2002) Opioid modulation of taste hedonics within the ventral striatum. Physiol Behav, in press.

Konradi C, Leveque JC, Hyman SE (1996) Amphetamine and dopamine-induced immediate early gene expression in striatal neurons depends on postsynaptic NMDA receptors and calcium. J Neurosci 16:4231-4239.

Koob GF, Le Moal M (2001) Drug addiction, dysregulation of reward, and allostasis. Neuropsychopharmacology 24:97-129.

Legault M, Wise RA (2001) Novelty-evoked elevations of nucleus accumbens dopamine: dependence on impulse flow from the ventral subiculum and glutamatergic neurotransmission in the ventral tegmental area. Eur J Neurosci 13:819-828.

Mulder AB, Hodenpijl MG, Lopes da Silva FH (1998) Electrophysiology of the hippocampal and amygdaloid projections to the nucleus accumbens of the rat: convergence, segregation, and interaction of inputs. J Neurosci 18:5095-5102.

O'Brien CP, Childress AR, McLellan T, Ehrman R (1992) A learning model of addiction. In: Addictive states (O'Brien CP, Jaffe J, eds), pp 157-177. New York: Raven.

O'Donnell P, Grace AA (1995) Synaptic interactions among excitatory afferents to NAc neurons: hippocampal gating of prefrontal cortical input. J Neurosci 15:3622-3639.

Owings DH, Morton ES (1998) Animal vocal communication: a new approach. New York: Cambridge UP.

Packard MG, White NM (1990) Lesions of the caudate nucleus selectively impair "reference memory" acquisition in the radial maze. Behav Neural Biol 53:39-50

Parkinson JA, Robbins TW, Everitt BJ (1999) Selective excitotoxic lesions of the nucleus accumbens core and shell differentially affect aversive Pavlovian conditioning to discrete and contextual cues. Psychobiology 27:256-266.

Paxinos G, Watson C (1998) A stereotaxic atlas of the rat brain. New York: Academic

Peciña S, Berridge KC (2000) Opioid eating site in nucleus accumbens shell mediates food intake and hedonic "liking": map based on microinjection Fos plumes. Brain Res 863:71-86.

Peciña S, Berridge KC, Parker LA (1997) Pimozide does not shift palatability: separation of anhedonia from sensorimotor suppression by taste reactivity. Pharmacol Biochem Behav 58:801-811.

Petrovich GD, Canteras NS, Swanson L (2001) Combinatorial amygdalar inputs to hippocampal domains and hypothalamic behavior systems. Brain Res Brain Res Rev 38:247-289.

Piazza PV, Rouge-Pont F, Deroche V, Maccari S, Simon H, Le Moal M (1996) Glucocorticoids have state-dependent stimulant effects on the mesencephalic dopaminergic transmission. Proc Natl Acad Sci USA 93:8716-8720.

Rada P, Tucci S, Murzi E, Hernandez L (1997) Extracellular glutamate increases in the lateral hypothalamus and decreases in the nucleus accumbens during feeding. Brain Res 768:338-340.

Rada PV, Mark GP, Hoebel BG (1998) Dopamine release in the nucleus accumbens by hypothalamic stimulation-escape behavior. Brain Res 782:228-234

Redgrave P, Prescott TJ, Gurney K (1999) Is the short-latency dopamine response too short to signal reward error? Trends Neurosci 22:146-151.

Reynolds SM, Berridge KC (2001) Fear and feeding in the nucleus accumbens shell: rostrocaudal segregation of GABA-elicited defensive behavior versus eating behavior. J Neurosci 21:3261-3270.

Robbins TW, Everitt BJ (1999) Drug addiction: bad habits add up. Nature 398:567-570.

Robinson TE, Berridge KC (1993) The neural basis of drug craving: an incentive-sensitization theory of addiction. Brain Res Rev 18:247-291.

Robinson TE, Berridge KC (2000) The psychology and neurobiology of addiction: an incentive-sensitization view. Addiction 95:91-117.

Rolls ET (1999) The brain and emotion. Oxford: Oxford UP.

Salamone JD (1994) The involvement of nucleus accumbens dopamine in appetitive and aversive motivation. Behav Brain Res 61:117-133.

Schoenbaum G, Chiba AA, Gallagher M (1999) Neural encoding in orbitofrontal cortex and basolateral amygdala during olfactory discrimination learning. J Neurosci 19:1876-1884.

Schultz W (2000) Multiple reward signals in the brain. Nat Rev Neurosci 1:199-207.

Seamans JK, Durstewitz D, Christie BR, Stevens CF, Sejnowski TJ (2001) DA D1/D5 receptor modulation of excitatory synaptic inputs to layer V prefrontal cortex neurons. Proc Natl Acad Sci USA 98:301-306.

Smith-Roe SL, Kelley AE (2000) Coincident activation of NMDA and dopamine D1 receptors within the nucleus accumbens core is required for appetitive instrumental learning. J Neurosci 20:7737-7742.

Solomon RL, Corbit JD (1974) An opponent-process theory of motivation: I. Temporal dynamics of affect. Psychol Rev 81:119-145.

Steiner JE, Glaser D, Hawilo ME, Berridge KC (2001) Comparative expression of hedonic impact: affective reactions to taste by human infants and other primates. Neurosci Biobehav Rev 25:53-74 
Stewart J, Wise RA (1992) Reinstatement of heroin self-administration habits: morphine prompts and naltrexone discourages renewed responding after extinction. Psychopharmacology 108:79-84.

Stratford TR, Kelley AE (1999) Evidence of a functional relationship between the NAc shell and lateral hypothalamus subserving the control of feeding behavior. J Neurosci 19:11040-11048.

Swanson LW (2000) Cerebral hemisphere regulation of motivated behavior. Brain Res 886:113-164.

Treit D, Pinel JP, Fibiger HC (1981) Conditioned defensive burying: a new paradigm for the study of anxiolytic agents. Pharmacol Biochem Behav 15:619-626.

Uslaner J, Badiani A, Norton CS, Day HE, Watson SJ, Akil H, Robinson TE (2001) Amphetamine and cocaine induce different patterns of c-fos mRNA expression in the striatum and subthalamic nucleus depending on environmental context. Eur J Neurosci 13:106-113.

Volkow ND, Wang GJ, Fowler JS, Logan J, Gatley SJ, Wong C, Hitzemann R, Pappas NR (1999) Reinforcing effects of psychostimulants in humans are associated with increases in brain dopamine and occupancy of D-2 receptors. J Pharmacol Exp Ther 291:409-415.
Wang J, O’Donnell P (2001) D(1) dopamine receptors potentiate NMDA-mediated excitability increase in layer $\mathrm{V}$ prefrontal cortical pyramidal neurons. Cereb Cortex 11:452-462.

White NM (1989) A functional hypothesis concerning the striatal matrix and patches: mediation of S-R memory and reward. Life Sci 45:1943-1957.

Wise RA (1985) The anhedonia hypothesis: Mark III. Behav Brain Sci 8:178-186.

Wyvell CL, Berridge KC (2000) Intra-nucleus accumbens amphetamine increases the conditioned incentive salience of sucrose reward: enhancement of reward "wanting" without enhanced "liking" or response reinforcement. J Neurosci 20:8122-8130.

Zahm DS (2000) An integrative neuroanatomical perspective on some subcortical substrates of adaptive responding with emphasis on the nucleus accumbens. Neurosci Biobehav Rev 24:85-105.

Zhang M, Kelley AE (2000) Enhanced intake of high-fat food after striatal mu-opioid stimulation: microinjection mapping and fos expression. Neuroscience 99:267-277. 